\title{
소결온도와 $\mathrm{Sb} / \mathrm{Bi}$ 비가 $\mathrm{ZnO}-\mathrm{Bi}_{2} \mathrm{O}_{3}-\mathrm{Sb}_{2} \mathrm{O}_{3}-\mathrm{Co}_{3} \mathrm{O}_{4}$ 바리스터의 미세구조와 입계 특성에 미치는 영향
}

\author{
홍연우 ${ }^{1, a}$, 신효순 ${ }^{1}$, 여동훈 ${ }^{1}$, 김진호 $^{2}$ \\ ${ }^{1}$ 한국세라믹기술원 미래융합세라믹본부 \\ 2 경북대학교 신소재공학부
}

\section{Effect of Sintering Temperature and $\mathrm{Sb} / \mathrm{Bi}$ Ratio on Microstructure and Grain Boundary Properties of $\mathrm{ZnO}-\mathrm{Bi}_{2} \mathrm{O}_{3}-\mathrm{Sb}_{2} \mathrm{O}_{3}-\mathrm{Co}_{3} \mathrm{O}_{4}$ Varistor}

\author{
Youn-Woo Hong ${ }^{1, a}$, Hyo-Soon Shin ${ }^{1}$, Dong-Hun Yeo ${ }^{1}$, and Jin-Ho Kim ${ }^{2}$ \\ ${ }^{1}$ Future Convergence Ceramic Division, Korea Institute of Ceramic Engineering and Technology, \\ Seoul 153-801, Korea \\ ${ }^{2}$ School of Materials Science and Engineering, Kyungpook National University, Daegu 702-701, Korea
}

(Received October 20, 2011; Revised November 18, 2011; Accepted November 23, 2011)

\begin{abstract}
In this study we aims to evaluate the effects of $1 / 3$ mol\% $\mathrm{Co}_{3} \mathrm{O}_{4}$ addition on the reaction, microstructure development, resultant electrical properties, and especially the bulk trap and grain boundary properties of $\mathrm{ZnO}-\mathrm{Bi}_{2} \mathrm{O}_{3}-\mathrm{Sb}_{2} \mathrm{O}_{3}(\mathrm{Sb} / \mathrm{Bi}=2.0$, 1.0, and 0.5) system (ZBS). The samples were prepared by conventional ceramic process, and characterized by XRD, density, SEM, I-V, impedance and modulus spectroscopy (IS \& MS) measurement. In addition of $\mathrm{Co}_{3} \mathrm{O}_{4}$ in $\mathrm{ZnO}^{-}-\mathrm{Bi}_{2} \mathrm{O}_{3}-\mathrm{Sb}_{2} \mathrm{O}_{3}$ (ZBSCo), the phase development, density, and microstructure were controlled by $\mathrm{Sb} / \mathrm{Bi}$ ratio. Pyrochlore on cooling was reproduced in all systems. The more homogeneous microstructure was obtained in ZBSCo ( $\mathrm{Sb} / \mathrm{Bi}=1.0)$ system. In ZBSCo, the varistor characteristics were improved drastically (non-linear coefficient $a=23 \sim 50$ ) compared to ZBS. Doping of $\mathrm{Co}_{3} \mathrm{O}_{4}$ to ZBS seemed to form $V_{o}^{\cdot}(0.33 \mathrm{eV})$ as dominant defect. From IS \& MS, especially the grain boundary of $\mathrm{Sb} / \mathrm{Bi}=0.5$ system is composed of electrically single barrier $(0.93 \mathrm{eV})$ and somewhat sensitive to ambient oxygen with temperature.
\end{abstract}

Keywords: $\mathrm{ZnO}$ varistor, $\mathrm{Co}_{3} \mathrm{O}_{4}$, Sintering, Electrical properties, Impedance spectroscopy

\section{1. 서 론}

$\mathrm{ZnO}$ 바리스터는 전력계통과 전자기기의 회로 등을 정전기 (electro-static discharge, $\mathrm{ESD}$ )나 과전압 혹 은 각종 써지 (surge)로부터 보호하는 소자로 폭 넓 게 사용되는 전자 세라믹 부품이다 [1-6]. $\mathrm{Bi}$ 계 $\mathrm{ZnO}$ 바리스터에서 결함과 입계특성은 첨가하는 도펀트

a. Corresponding author; hyw-kea@kicet.re.kr (dopants)에 따라 다양하게 변하며, 특히 $\mathrm{Co}$ 와 $\mathrm{Mn}$ 은 계면상태 (interface states) 준위를 형성하여 비선형 성을 크게 개선한다 [1-6]. $\mathrm{ZnO}$ 바리스터에서 액상 소결 첨가제인 $\mathrm{Bi}_{2} \mathrm{O}_{3}$ 를 사용할 경우 $\mathrm{ZnO}$ 의 입성장을 제어할 목적으로 $\mathrm{Sb}_{2} \mathrm{O}_{3}$ 를 함께 첨가하며, 이에 따라 $\mathrm{Sb} / \mathrm{Bi}$ 비가 계의 상발달, 치밀화, 소결, 미세구조 및 전기적 특성을 크게 좌우하는 것으로 알려져 있다 [7-12]. 또한 $\mathrm{ZnO}-\mathrm{Bi}_{2} \mathrm{O}_{3}-\mathrm{Sb}_{2} \mathrm{O}_{3}(\mathrm{ZBS})$ 계에 소량의 첨 가물들 $(\mathrm{Mn}, \mathrm{Co}, \mathrm{Cr}, \mathrm{Ni}$ 등)은 2차상인 파이로클로어 
(pyrochlore, $\mathrm{Zn}_{2} \mathrm{Bi}_{3} \mathrm{Sb}_{3} \mathrm{O}_{14}$ )의 생성과 분해반응 온도를 변화시켜 미세구조를 제어할 뿐 아니라 바리스터 특 성에 영향을 미친다 [7-13]. 일반적으로 $\mathrm{ZnO}$ 바리스 터의 도너형 결함은 $\mathrm{Zn}_{\mathrm{i}}$ 와 $\mathrm{V}_{\mathrm{o}}$ 이 대표적이며, $\mathrm{ZnO}$ 바 리스터의 비선형성에 영향을 미치는 것으로 보고되고 있다 [1,14-18]. 또한 입계는 크게 두 종류로 $\mathrm{ZnO}-\mathrm{ZnO}$ 의 동종접합 계면과 $\mathrm{ZnO}-\mathrm{Bi}_{2} \mathrm{O}_{3}-\mathrm{ZnO}$ 의 이종접합 계 면으로 분류되며, 전자는 비선형 전류-전압 특성을 나타내고, 후자는 전류-전압 곡선에서 누설 전류항목 과 관계되는 입계로 알려져 있다 [1,4,19-23]. 이러한 입계는 소량 첨가되는 도펀트와 그 조합에 따라 크게 달라지기 때문에 각 도펀트의 역할에 대하여 많은 연 구가 진행되어 왔다 [1,14-16,20-23]. Co의 함량이 1 $\mathrm{mol} \%$ 이상일 경우 $\mathrm{ZnO}$ 입자의 비저항이 높아져 고 전류 영역 (반전영역, up-turn region)의 비선형성을 떨어뜨리는 원인으로 작용한다 [24]. 복잡한 미세구조 를 갖는 ZBS계 바리스터의 결함과 입계 특성은 다양 한 유전 함수들을 함께 사용하여 측정 주파수 대역과 온도 범위에 따라 종합적으로 분석할 수 있는 것으로 알려져 있다 [12,15,19-23]. 특히 Co을 첨가한 계에 대 한 소결과 결함 및 입계 특성을 종합적으로 분석하여 발표한 내용은 미진한 실정이다. 따라서 본 연구에서 는 ZBS계에 $\mathrm{Sb} / \mathrm{Bi}$ 비를 달리한 후 $\mathrm{CO}_{3} \mathrm{O}_{4}$ 를 $1 / 3$ $\mathrm{mol} \%$ 첨가한 4성분 계에 대하여 소결과 전기적 특성 을 살펴봄으로써 $\mathrm{Co}$ 의 역할에 대하여 보다 상세하게 조사하였다.

\section{2. 실험 방법}

본 연구에서는 순도 $99.9 \%$ (고순도 화학, 일본)의 $\mathrm{ZnO}, \mathrm{Bi}_{2} \mathrm{O}_{3}, \mathrm{Sb}_{2} \mathrm{O}_{3}, \mathrm{Co}_{3} \mathrm{O}_{4}$ 를 사용하여 모상인 $\mathrm{ZnO}$ 에 $\mathrm{Sb} / \mathrm{Bi}=2.0 \quad\left(1.0 \quad \mathrm{~mol} \% \quad \mathrm{Bi}_{2} \mathrm{O}_{3}, \quad 2.0 \quad \mathrm{~mol} \% \quad \mathrm{Sb}_{2} \mathrm{O}_{3}, \quad 1 / 3\right.$ $\left.\mathrm{mol} \% \mathrm{Co}_{3} \mathrm{O}_{4}\right), \mathrm{Sb} / \mathrm{Bi}=1.0\left(1.5 \mathrm{~mol} \% \mathrm{Bi}_{2} \mathrm{O}_{3}, 1.5 \mathrm{~mol} \%\right.$ $\left.\mathrm{Sb}_{2} \mathrm{O}_{3}, 1 / 3 \mathrm{~mol} \% \mathrm{Co}_{3} \mathrm{O}_{4}\right), \mathrm{Sb} / \mathrm{Bi}=0.5\left(2.0 \mathrm{~mol} \% \mathrm{Bi}_{2} \mathrm{O}_{3}\right.$, $\left.1.0 \mathrm{~mol} \% \quad \mathrm{Sb}_{2} \mathrm{O}_{3}, \quad 1 / 3 \quad \mathrm{~mol} \% \quad \mathrm{Co}_{3} \mathrm{O}_{4}\right)$ 인 3 종류의 ZBSCo 조성을 제작하여 일반적인 세라믹 공정으로 혼합하여 출발 원료로 사용하였다. 소결을 위하여 성 형체는 출발 원료를 $\Phi 11 \mathrm{~mm}$ 의 원통형 금형에 장입하 여 먼저 $25 \mathrm{MPa}$ 로 1축 가압 성형한 후 $98 \mathrm{MPa}$ 로 정 수압 처리하여 제조하였다. 성형 시편은 $700 ~ 1,300^{\circ} \mathrm{C}$ 에서 1 시간 공기 중에서 소결하였으며, 승온 시 $500^{\circ} \mathrm{C}$ 에서 $\mathrm{Sb}$ 의 산화를 위하여 1 시간 유지하였으며, 승온 및 냉각 속도는 $5^{\circ} \mathrm{C} / \mathrm{min}$.로 고정하였다. 소결 시편은
약 $1.0 \mathrm{~mm}$ 두께로 하여 양면에 $\mathrm{Ag}$ 전극 (ohmic contact용)을 직경이 $\Phi 6 \mathrm{~mm}$ 가 되게 실크 스크린으로 도포하여 소성로에 넣고 $600^{\circ} \mathrm{C}$ 에서 10 분 열처리하여 전기적 특성 측정용 시편으로 준비하였다.

각 조성의 소결 상변화를 관찰하기 위하여 $\mathrm{X}$-선 회절 분석기 (M03X-HF, MAC Science Co. Ltd., Japan)로 분석하였으며, 밀도는 Archimedes법으로 구 하였다. 또한 소결 시편의 미세구조는 $0.4 \%$ 염산 수 용액으로 에칭하여 SEM (S-4200, Hitachi, Japan)으 로 관찰하였으며, 대략적인 상의 분포를 살펴보기 위 하여 BEI (Backscattered Electron Image: RBH-4200 $5 \mathrm{MC}$, Robinson, Australia)로 관찰하였다.

전류-전압(I-V) 특성은 High voltage source meter (Keithley, 237, USA)를 사용하였으며, 바리스터의 비 선형 계수 $(\mathrm{a})$ 는 $\mathrm{I}-\mathrm{V}$ 측정값에 시편의 전극 단면적과 두께를 대입한 전류밀도-전기장 $(\mathrm{J}-\mathrm{E})$ 곡선으로부터 $\mathrm{J}=\mathrm{CE}^{\mathrm{a}}, \mathrm{a}=\log \left(\mathrm{J}_{2} / \mathrm{J}_{1}\right) / \log \left(\mathrm{E}_{2} / \mathrm{E}_{1}\right)$ 에 따라 구하였다. 여기 서 $\mathrm{J}_{1}=1\left(\mathrm{~mA} / \mathrm{cm}^{2}\right), \mathrm{J}_{2}=10\left(\mathrm{~mA} / \mathrm{cm}^{2}\right)$ 이며, $\mathrm{E}_{1}$ 과 $\mathrm{E}_{2}$ 는 각각 전류밀도 $\mathrm{J}_{1}, \mathrm{~J}_{2}$ 에서의 전장의 세기 $(\mathrm{V} / \mathrm{cm})$ 이다. 입계당 항복전압 $\left(\mathrm{V}_{\mathrm{gb}}\right)$ 은 항복 전압 $\left(\mathrm{V}_{\mathrm{b}}, 1 \mathrm{~mA} / \mathrm{cm}^{2}\right.$ 에 서의 전압), 시편의 두께 $(\mathrm{t}), \mathrm{ZnO}$ 입자의 평균 입경 $(\bar{d})$ 으로부터 $\mathrm{V}_{\mathrm{gb}}=\mathrm{V}_{\mathrm{b}} \cdot \bar{d} / \mathrm{t}$ 로 구하였다. 누설 전류 밀도 (leakage current density: $\mathrm{J}_{\mathrm{L}}$ )는 $0.8 \mathrm{~V}_{\mathrm{b}}$ 에서의 전류 밀도 값으로 정하였다. 또한 pre-breakdown 영역의 $\mathrm{J}-\mathrm{E}$ 곡선의 기울기로부터 상온 비저항, $\rho \mathrm{gb}(\Omega \mathrm{cm})$ 를 구하였다.

결함과 입계 특성을 살펴보기 위한 impedance and modulus spectroscopy (IS \& MS)는 Impedance/gain phase analyzer (Hewlett Packard, 4194A, Japan)를 사 용하여 $-195 \sim 507^{\circ} \mathrm{C}$ 까지 $20^{\circ} \mathrm{C}$ 간격으로 승온하면서 측정하였다 [12]. IS \& MS 분석법에서는 일반적으로 아래 2 가지의 유전함수가 사용된다.

$$
\begin{aligned}
& Z^{*}=Y^{*-1}=\left[j \omega C_{0} \varepsilon^{*}\right]^{-1}=Z^{\prime}-j Z^{\prime \prime} \\
& M^{*}=\varepsilon^{*-1}=j \omega C_{0} Z^{*}=M^{\prime}+j M^{\prime \prime}
\end{aligned}
$$

여기서, $\omega=$ 각주파수 $(2 \pi \mathrm{f}, \mathrm{f}=$ 주파수 $), \mathrm{C}_{0}=\varepsilon_{0} \cdot \mathrm{A} / \mathrm{t} \quad\left(\varepsilon_{0}=\right.$ 진공유전율, $\mathrm{A}=$ 단면적, $\mathrm{t}=$ 시편두께 $), \mathrm{j}=\sqrt{-1}$ 이다.

주파수는 $100 \mathrm{~Hz} \sim 15 \mathrm{MHz}$ 대역에서, 측정온도는 $-195 \sim 507^{\circ} \mathrm{C}$ 범위에서 각 유전 함수 별로 주파수 응 답도 (frequency explicit plot)를 이용하여 각 피크의 최댓값에 대한 피크 온도 $\mathrm{T}_{\mathrm{p}}$ 와 피크 주파수 $\mathrm{f}_{\max }$ 를 구하고, 임피던스 (impedance)와 모듈러스 (modulus) 
데이터에서 각 허수부의 최댓값 $\mathrm{Z}^{\prime \prime}{ }_{\max }$ 와 $\mathrm{M}^{\prime \prime}{ }_{\max }$ 를 그 래프 상에서 구하여 식 (3)을 이용하여 입계 저항 $\left(\mathrm{R}_{\mathrm{gb}}\right)$ 과 정전용량 $\left(\mathrm{C}_{\mathrm{gb}}\right)$ 을 추출하였다 $[12,20]$.

$$
Z_{\max }^{\prime \prime}=\frac{R}{2}, \quad M_{\max }^{\prime \prime}=\frac{C_{0}}{2 C}
$$

이렇게 구한 $\mathrm{T}_{\mathrm{p}}$ 와 $\tau^{-1}=\omega_{\max }=2 \pi \mathrm{f}_{\max }, Z^{\prime \prime}{ }_{\max }, \mathrm{M}^{\prime \prime}{ }_{\text {max }}$ 값은 아레니우스(Arrehnius)식 $\left(\tau=\tau_{0} \exp \left(E_{a} / k T\right), \rho=\rho_{0} \exp \left(E_{a} / k T\right)\right.$, $\tau=$ 완화시간, $\rho=$ 비저항 $(\Omega \mathrm{cm}), \mathrm{E}_{\mathrm{a}}=\tau$ 혹은 $\mathrm{\rho}$ 에 대한 활 성화 에너지, $k:=$ 볼쯔만 상수 $\left(8.62 \times 10^{-5}(\mathrm{eV} / \mathrm{K})\right), \mathrm{T}=$ 온 도 $(\mathrm{K}))$ 을 이용하여 각각 $\ln \tau$ vs. $1,000 / \mathrm{T}$ 및 $\ln \rho$ vs. $1,000 / \mathrm{T}$ 그래프를 통하여 그 기울기로부터 상온 이하 의 값에서는 결함 준위 (혹은 이온화 에너지, $\mathrm{E}_{\mathrm{bt}}$ )와 상온 이상에서는 입계 활성화 에너지 $\left(\mathrm{E}_{\mathrm{a}}\right)$ 를 구하는데 사용하였다 [12,20].

\section{3. 결과 및 고찰}

\subsection{XRD 특성}

그림 1에는 (a) ZBSCo ( $\mathrm{Sb} / \mathrm{Bi}=2.0$ )과 (b) $\mathrm{ZBSCo}$ $(\mathrm{Sb} / \mathrm{Bi}=0.5) \quad$ 시편을 $700 \sim 1,300^{\circ} \mathrm{C}$ 로 소결한 후 서냉 하였을 때 나타나는 XRD 패턴을 나타낸 것이다. 그 리고 표 1 에는 $\mathrm{ZBSCo}(\mathrm{Sb} / \mathrm{Bi}=2.0,1.0,0.5)$ 계 전체에 대한 2 차상의 변화를 정리하였다.

$\mathrm{ZBSCo}$ 계의 2차상으로는 $\mathrm{Sb} / \mathrm{Bi}$ 비와 관계없이 전 체 계에서 파이로클로어(Py)가 생성되었으며, $\mathrm{a}^{-}$스피 넬(asp), $\beta$-스피넬( $\beta \mathrm{sp}), \quad \beta-\mathrm{Bi}_{2} \mathrm{O}_{3}, \quad \gamma-\mathrm{Bi}_{2} \mathrm{O}_{3}, \quad$ 미량의 $\mathrm{Bi}-$ rich 상이 존재하였다. 상발달 과정은 $\mathrm{Sb} / \mathrm{Bi}$ 비에 따라 다르게 나타났다. $\mathrm{Sb} / \mathrm{Bi}=2.0$ 의 경우, $700^{\circ} \mathrm{C}$ 에서 파이로클로어가 생성되고 $800^{\circ} \mathrm{C}$ 에서 $\mathrm{a}^{-}$스피넬이 추가 적으로 생성되었다가 $1,000^{\circ} \mathrm{C}$ 이후에는 $\mathrm{a}$-스피넬이 사라지고 $\beta$-스피넬이 생성되면서 극미량의 $\mathrm{Bi}-$ rich 상이 존재하였다. $\mathrm{Sb} / \mathrm{Bi}=1.0$ 의 경우, $900^{\circ} \mathrm{C}$ 까지 $\mathrm{Py}$ 만 존재하다가 $1,000^{\circ} \mathrm{C}$ 이후에는 $\mathrm{Py}$ 의 분해에 의한 $\beta \mathrm{sp}$ 와 미량의 $\mathrm{Bi}-$ rich 상이 함께 존재하였다. $\mathrm{Sb} / \mathrm{Bi}=0.5$ 인 조성은 $\mathrm{Py}$ 가 전체 온도에서 존재하고 $\mathrm{Py}$ 형성에 관여하지 않은 잔류 $\mathrm{Bi}_{2} \mathrm{O}_{3}$ 상은 $800^{\circ} \mathrm{C}$ 까지 $\mathrm{\gamma}-\mathrm{Bi}_{2} \mathrm{O}_{3}$ 상 으로, $900^{\circ} \mathrm{C}$ 이상에서는 $\beta-\mathrm{Bi}_{2} \mathrm{O}_{3}$ 상으로 존재하였다 (그림 1, 표 1). 따라서 파이로클로어는 $\mathrm{Sb} / \mathrm{Bi}$ 비와 관계없이 전체 계에서 생성되었으며, $\mathrm{Sb} / \mathrm{Bi} \geq 1.0$ 일 때 $\beta$-스피넬이, $\mathrm{Sb} / \mathrm{Bi}=0.5$ 일 때 $\beta$-스피넬은 사라지고 $\beta$
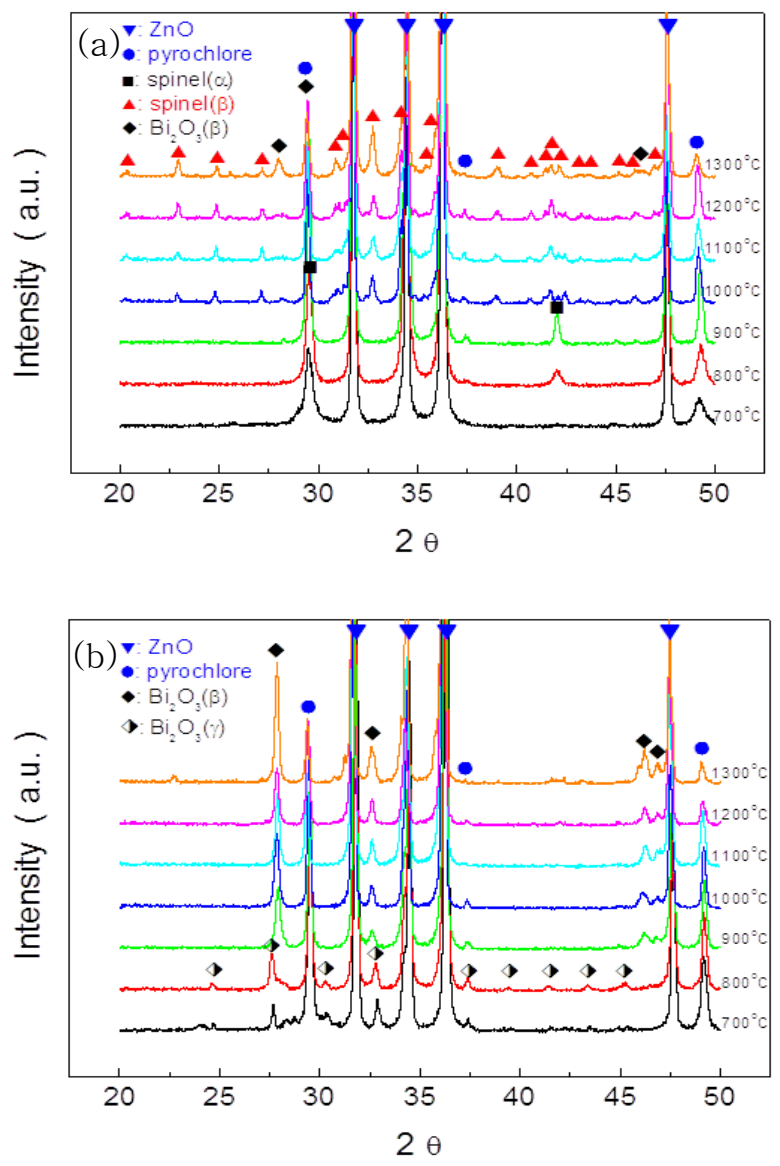

Fig. 1. XRD patterns of ZBSCo system (a) $\mathrm{Sb} / \mathrm{Bi}=2.0$ and (b) $\mathrm{Sb} / \mathrm{Bi}=0.5$ with sintering temperatures.

Table 1. Secondary phases in ZBSCo $(\mathrm{Sb} / \mathrm{Bi}=2.0,1.0$, and 0.5) sintered at various temperatures. (Py: $\mathrm{Zn}_{2} \mathrm{Sb}_{3} \mathrm{Bi}_{3} \mathrm{O}_{14}, \mathrm{a}$ sp: $\quad a-Z_{7} \mathrm{Sb}_{2} \mathrm{O}_{12}, \quad \beta s p: \quad \beta-Z_{7} \mathrm{Sb}_{2} \mathrm{O}_{12}, \quad \beta: \quad \beta-\mathrm{Bi}_{2} \mathrm{O}_{3}, \quad \gamma: \quad \gamma$ $-\mathrm{Bi}_{2} \mathrm{O}_{3}$, ( ): trace of each phase ( $\mathrm{Bi}$ : $\mathrm{Bi}-$ rich phase)).

\begin{tabular}{ccccc}
\hline $\mathrm{Sb} / \mathrm{Bi}$ & $700{ }^{\circ} \mathrm{C}$ & $800{ }^{\circ} \mathrm{C}$ & $900{ }^{\circ} \mathrm{C}$ & $1,000 \sim 1,300{ }^{\circ} \mathrm{C}$ \\
\cline { 1 - 1 } 2.0 & & $\mathrm{Py}+\mathrm{asp}$ & $\mathrm{Py}+\beta \mathrm{sp}+(\mathrm{Bi})$ \\
\cline { 3 - 4 } 1.0 & & $\mathrm{Py}$ & $\mathrm{Py}+(\beta \mathrm{sp})+(\mathrm{Bi})$ \\
\hline 0.5 & $\mathrm{Py}+\gamma$ & & $\mathrm{Py}+\beta$ \\
\hline
\end{tabular}

$-\mathrm{Bi}_{2} \mathrm{O}_{3}$ 를 우선적으로 생성하였다. 전체적으로 $\mathrm{ZBSCo}$ 계의 상발달 과정은 $\mathrm{ZBS}$ 계와 거의 동일하였다 $[9,11]$. 이는 $\mathrm{Cr}$ 을 첨가한 $\mathrm{ZBSCr}$ 계의 $\mathrm{Py}$ 생성이 $\mathrm{Sb} / \mathrm{Bi}$ 비 에 관계없이 생성되는 것과 동일한 거동이지만, $\mathrm{a}^{-}$스 피넬과 $\delta-\mathrm{Bi}_{2} \mathrm{O}_{3}$ 를 우선적으로 생성하는 것과는 차이 
가 나는 현상이다 [23]. 또한 $\mathrm{Mn}$ 를 첨가한 ZBSM계 에서 $a^{-}$스피넬의 생성과 안정화에 기여하는 $\mathrm{Mn}$ 의 역 할과 차이가 나며 [11], $\mathrm{Ni}$ 을 첨가한 $\mathrm{ZBSN}$ 계의 $\mathrm{Sb} / \mathrm{Bi} \geq 1.0$ 일 때 $\beta$-스피넬을, $\mathrm{Sb} / \mathrm{Bi}=0.5$ 일 때 $\mathrm{a}$-스피 넬을 형성하는 상발달 과정과도 다른 양상이다 [21].

뿐만 아니라 $1,000^{\circ} \mathrm{C}$ 이하 즉, $900^{\circ} \mathrm{C}$ 의 상발달 과정 ( $\mathrm{Sb} / \mathrm{Bi}=2.0, \mathrm{Py}+\mathrm{asp} ; \mathrm{Sb} / \mathrm{Bi}=1.0, \mathrm{Py} ; \mathrm{Sb} / \mathrm{Bi}=0.5, \mathrm{Py}+$ $\beta)$ 을 볼 때 $1,000^{\circ} \mathrm{C}$ 이상에서 $\mathrm{Sb} / \mathrm{Bi}$ 비에 따른 치밀 화 거동이 사뭇 달라질 것이라 예상할 수 있다.

\section{2 밀도 변화}

그림 2 는 $\mathrm{Sb} / \mathrm{Bi}$ 비에 따른 $\mathrm{ZBSCo}$ 계의 소결 온도 별 상대 밀도를 측정한 것이다.

$Z \mathrm{BS}$ 계에 $\mathrm{Co}$ 를 첨가할 경우, $\mathrm{Sb} / \mathrm{Bi}$ 비에 따라 소결 온도에 대한 밀도는 다양하게 나타났다. $1,200^{\circ} \mathrm{C}$ 이상 에서는 $\mathrm{Sb} / \mathrm{Bi}$ 비와 관계없이 상대밀도가 감소하는 일 정한 경향을 나타내는 반면 $700 \sim 1,200^{\circ} \mathrm{C}$ 소결 구간 에서는 $\mathrm{Sb} / \mathrm{Bi}$ 비에 따라 상당한 차이를 보이고 있다. 먼저 $\mathrm{Sb} / \mathrm{Bi}=2.0$ 의 경우, 그림 1 과 표 1 에서 보듯이 파 이로클로어 $\left(\mathrm{Py}, \mathrm{d}=7.86 \mathrm{~g} / \mathrm{cm}^{3}\right.$ )와 스피넬 $(\mathrm{asp}, \mathrm{d}=6.25$ $\mathrm{g} / \mathrm{cm}^{3}$ )의 생성으로 $900^{\circ} \mathrm{C}$ 까지 치밀화가 억제(상대밀 도 $59 \%)$ 되고, $1,000^{\circ} \mathrm{C}$ 에서 파이로클로어의 분해로 생 성된 $\mathrm{Bi}-\mathrm{rich}$ 액상 $\left(\mathrm{\beta}-\mathrm{Bi}_{2} \mathrm{O}_{3}, \mathrm{~d}=9.17 \mathrm{~g} / \mathrm{cm}^{3}\right)$ 에 의해 치밀화가 촉진됨에 따라 밀도는 $87 \%$ 로 높아졌다. 그 러나 $1,000^{\circ} \mathrm{C}$ 에서도 치밀화가 완전하지 않아 $1,200^{\circ} \mathrm{C}$ 가 되어서야 최고 상대밀도(94\%)를 나타내었는데 이 는 다음에 살펴보겠지만 상발달 과정과 밀접한 연관 을 갖는 미세구조 발달 때문이다 (그림 3(a) 참고). $\mathrm{Sb} / \mathrm{Bi}=1.0$ 인 조성의 경우, $\mathrm{Sb} / \mathrm{Bi}=2.0$ 과 마찬가지로 $900^{\circ} \mathrm{C}$ 까지 거의 치밀화가 억제되었는데, 이는 $\mathrm{Co}$ 의 첨가에 의해 $\mathrm{Py}$ 의 분해를 효과적으로 촉진하지 못하 는 것을 알 수 있다. $1,000^{\circ} \mathrm{C}$ 에서 파이로클로어의 분 해로 치밀화가 완전히 진행되어 $96 \%$ 의 상대밀도를 나타내면서 소결온도가 높아짐에 따라 소폭의 밀도 감소를 나타냈다. $\mathrm{Sb} / \mathrm{Bi}=0.5$ 는 $800^{\circ} \mathrm{C}$ 에서 $90 \%$ 의 높은 상대밀도를 보이는데 이는 일반적으로 ZBS계 및 여 기에 $\mathrm{Mn}$ 또는 $\mathrm{Ni}$ 를 첨가한 계에서 파이로클로어 생 성에 참여하지 않은 잔류 $\mathrm{Bi}_{2} \mathrm{O}_{3}$ 에 의해 상대적으로 높은 상대밀도를 나타내는 현상과 동일한 거동이며, $\mathrm{Cr}$ 첨가 효과와 다소 차이를 보인다 [9,11,21,23]. 소 결온도가 높아짐에 따라 $\mathrm{Bi}-\mathrm{rich}$ 상의 휘발에 의한 밀도감소가 $\mathrm{Sb} / \mathrm{Bi}=2.0$ 보다 더 빠르게 진행되었다. 따라서 $\mathrm{ZBS}$ 계에 $\mathrm{Co}$ 를 첨가할 경우, 그 밀도 변화는

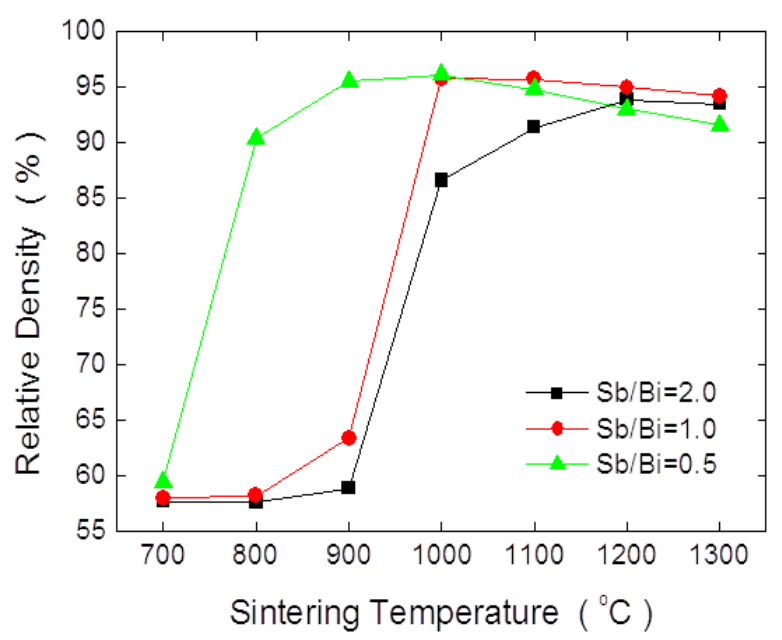

Fig. 2. Relative density of ZBSCo $(\mathrm{Sb} / \mathrm{Bi}=2.0,1.0$, and $0.5)$ sintered at various temperatures.

$\mathrm{Sb} / \mathrm{Bi}$ 비에 의해 크게 달라지는 것을 확인할 수 있었 으며, 보다 높은 밀도를 확보하기 위해서는 $\mathrm{Sb} / \mathrm{Bi} \leq$ 1.0 인 조성을 확보하는 것이 유리할 것으로 판단된다.

\section{3 미세구조}

그림 3은 $Z \mathrm{BSCo}(\mathrm{Sb} / \mathrm{Bi}=2.0,1.0,0.5)$ 계를 $1,000^{\circ} \mathrm{C}$ 에 서 1 시간 소결한 시편의 미세구조를 나타낸 것이다. $\mathrm{ZnO}$ 결정립은 짙은 회색, $\mathrm{Bi}-$ rich상은 흰색, 파이로클 로어(Py)와 스피넬( $\beta \mathrm{sp})$ 은 모두 $\mathrm{ZnO}$ 보다 옅은 회색 으로 보이지만 그림 3(a)에서와 같이 파이로클로어가 스피넬보다 더 옅은 회색으로 구분된다 $[9,11,21,23]$.

그림 $3(\mathrm{a})$ 와 같이 $\mathrm{Sb} / \mathrm{Bi}=2.0$ 인 조성에서 스피넬 $(\beta$ $\mathrm{sp})$ 은 무정형의 막대모양을 가지면서 그 주위에 파이 로클로어(Py)가 연이어 인접해 있으면서 $\mathrm{ZnO}$ 입자가 큰 것이 특징이다 [9,21]. $\mathrm{Sb} / \mathrm{Bi}=1.0$ (그림 $3(\mathrm{~b})$ )의 경 우, 전체적으로 파이로클로어가 대부분으로 $\mathrm{ZnO}$ 입 계 에 균일하게 분포하여 $\mathrm{ZnO}$ 입성장을 효과적으로 억 제시키고 그 분포를 균일하게 하였다. $\mathrm{Sb} / \mathrm{Bi}=0.5$ (그 림 3(c))에서는 파이로클로어 생성에 참여하지 않은 여분의 $\mathrm{Bi}-$ rich 액상으로 말미암아 입성장이 상당히 일어난 것을 볼 수 있다. 그림 3 에서 선형 교차법으로 계산한 $\mathrm{ZnO}$ 의 평균입경은 각각 $6.8 \mu \mathrm{m}(\mathrm{Sb} / \mathrm{Bi}=2.0)$, $2.7 \mu \mathrm{m}(\mathrm{Sb} / \mathrm{Bi}=1.0), 9.8 \mu \mathrm{m}(\mathrm{Sb} / \mathrm{Bi}=0.5)$ 이다.

$\mathrm{Sb} / \mathrm{Bi}=2.0$ (그림 $3(\mathrm{a})$ )의 경우, $\mathrm{ZnO}$ 의 평균입경이 $6.8 \mu \mathrm{m}$ 로 다소 큰 이유로는 가열 시 파이로클로어의 

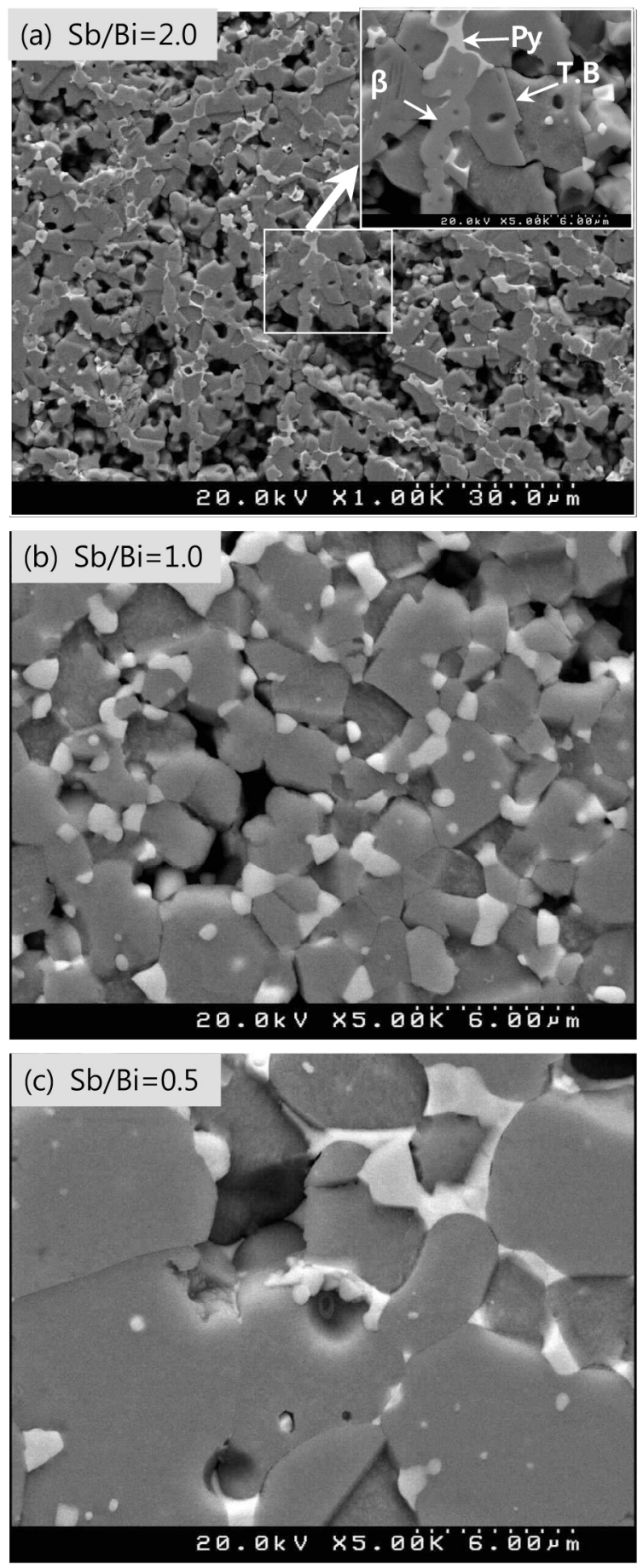

Fig. 3. Microstructure of ZBSCo ( $\mathrm{Sb} / \mathrm{Bi}=2.0,1.0$, and 0.5) systems sintered at $1,000^{\circ} \mathrm{C}$.

분해반응으로 생성되는 $\mathrm{Bi}$-rich 액상(이와 병행하여 막대형 스피넬( $\beta \mathrm{sp})$ 이 함께 인접하여 존재함)이 그
주위의 $\mathrm{ZnO}$ 입자들을 국부적으로 끌어당겨 뭉치는 현상을 초래함에 따라 미세구조적으로는 불균일하게 하여 상대밀도를 크게 낮추지만 $(87 \%)$, 국부적으로 입 성장을 보다 활발하게 함에 따라 그 평균입경이 크게 계산된 것으로 보인다 [9,21]. 이와 같은 치밀화 억제 현상은 $1,200^{\circ} \mathrm{C}$ 에서 최고 상대밀도가 되는 원인이기 도 하다. $\mathrm{Sb} / \mathrm{Bi}=1.0$ 의 경우, $\mathrm{Py}$ 만으로도 바리스터의 미세구조를 가장 균일하게 만들 수 있는 조건임을 알 수 있다. 이는 $\mathrm{ZBS}(\mathrm{Sb} / \mathrm{Bi}=1.0)$ 3성분 계와 여기에 $\mathrm{Ni}$ 를 첨가한 계보다 크게 개선된 결과일 뿐 아니라 동 질이상인 $\mathrm{a}$-스피넬의 $\mathrm{ZnO}$ 입성장 억제 효과로 말미 암아 균일한 미세구조를 얻을 수 있는 $\mathrm{Cr}$ 이나 $\mathrm{Mn}$ 을 첨가한 계와 비견할 수 있는 조건이다 [9,11,21,23].

$\mathrm{Sb} / \mathrm{Bi}=0.5$ 인 경우, 파이로클로어 생성에 참여하지 않은 잉여 $\mathrm{Bi}-$ rich 액상으로 말미암아 계의 치밀화는 $800^{\circ} \mathrm{C}$ 부터 크게 일어나 $\mathrm{ZnO}$ 입성장을 촉진하지만, 입 성장 제어 효과를 가지는 $\mathrm{a}$-스피넬이 없는 계이므로 균일한 미세구조를 확보하기에는 다소 부족한 경우라 사료된다.

따라서 전체적으로 그림 3 에서 보듯이 $\mathrm{ZBS}$ 계에 $\mathrm{Co}$ 를 첨가하면 $\mathrm{Sb} / \mathrm{Bi}$ 비에 따라 그 미세구조는 크게 달라지며, $\mathrm{Sb} / \mathrm{Bi}=1.0$ 인 계에서 가장 균일한 미세구조 를 얻을 수 있었다. 그러므로 $\mathrm{ZnO}$ 바리스터 조성을 개발하는 단계에서 $\mathrm{Co}_{3} \mathrm{O}_{4}$ 를 첨가제로 사용할 경우 $\mathrm{Sb} / \mathrm{Bi}$ 비를 잘 고려해서 상발달과 치밀화 및 미세구조 의 균일화를 유도해야 할 것으로 판단된다.

\subsection{I-V 특성}

그림 4 는 $1,000^{\circ} \mathrm{C}$ 에서 소결한 시편의 $\mathrm{J}-\mathrm{E}$ 특성 (a) 과 각 소결 온도별 $\mathrm{J}-\mathrm{E}$ 곡선으로부터 계산한 비선형 계수 $(\mathrm{a})$ 를 $\mathrm{Sb} / \mathrm{Bi}$ 비에 따라 그래프(b)로 나타낸 것이 며, 표 2 에는 $1,000^{\circ} \mathrm{C}$ 의 결과를 요약해 놓았다.

그림 4(a)에서 보듯이 $\sim 1 \mu \mathrm{A} / \mathrm{cm}^{2}$ 이하의 pre-breakdown 영역의 절연 저항은 $\mathrm{Sb} / \mathrm{Bi}$ 비가 낮아짐에 따라 $4.6 \rightarrow 7.7 \rightarrow$ $13 \times 10^{9} \Omega \mathrm{cm}$ 로 증가하는 경향을 보였는데, 이는 ZBBS계와 여 기에 $\mathrm{Ni}$ 를 첨가할 때와 같은 경향이다 [12,21]. $\mathrm{Sb} / \mathrm{Bi}$ 비 가 낮아질수록 비선형 계수 $(\mathrm{a})$ 는 $23 \rightarrow 47 \rightarrow 50$ 으로 증 가하고, 단위 입계 당 항복전압 $\left(\mathrm{V}_{\mathrm{gb}}\right)$ 은 $1.7 \rightarrow 1.0 \rightarrow 3.5$ $\mathrm{V}$ 로 낮아졌다가 높아지지만, 누설전류 $\left(\mathrm{J}_{\mathrm{L}}\right)$ 는 $24 \rightarrow 8 \rightarrow$ $0.8 \mu \mathrm{A} / \mathrm{cm}^{2}$ 로 낮아졌다 (표 2 참고).

바리스터 특성이 우수할수록 비선형성은 좋고 절연 저항은 높아지며 누설전류는 낮아지는 전형적인 특성 을 나타내었다. 

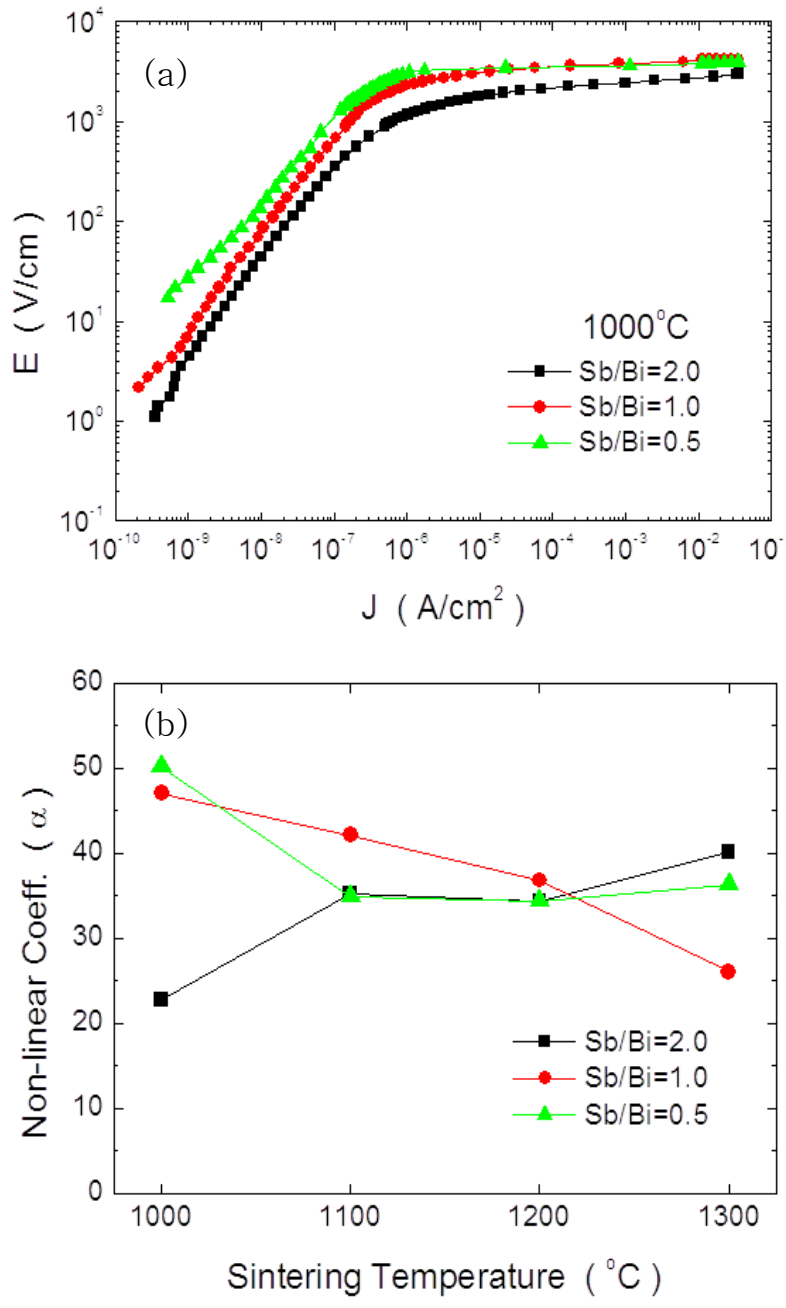

Fig. 4. (a) $\mathrm{J}-\mathrm{E}$ characteristics of $\mathrm{ZBSCo}(\mathrm{Sb} / \mathrm{Bi}=2.0$, 1.0, and 0.5 ) sintered at $1,000^{\circ} \mathrm{C}$. (b) Non-linear coefficient a with sintering temperatures.

Table 2. Summary of J-E characteristics of ZBSCo sintered at $1,000^{\circ} \mathrm{C}$.

\begin{tabular}{|c|c|c|c|c|c|}
\hline $\begin{array}{l}\mathrm{Sb} / \mathrm{Bi} \\
\text { ratio }\end{array}$ & $a$ & $\begin{array}{l}V_{b} \\
(\mathrm{~V})\end{array}$ & $\begin{array}{l}V_{g b} \\
(\mathrm{~V})\end{array}$ & $\begin{array}{c}J_{L} \\
\left(\mu \mathrm{A} / \mathrm{cm}^{2}\right)\end{array}$ & $\begin{array}{c}\rho g b \\
(\Omega \mathrm{cm})\end{array}$ \\
\hline 2.0 & 23 & 276 & 1.7 & 24 & $4.6 \times 10^{9}$ \\
\hline 1.0 & 47 & 436 & 1.0 & 8 & $7.7 \times 10^{9}$ \\
\hline 0.5 & 50 & 417 & 3.5 & 0.8 & $\begin{array}{c}1.3 \times 10^{1} \\
0\end{array}$ \\
\hline
\end{tabular}

한편 그림 4(b)와 같이 소결 온도에 따른 비선형 계수의 변화는 $\mathrm{Sb} / \mathrm{Bi}$ 비에 따라 다소 다르게 나타났
다. 먼저 $\mathrm{Sb} / \mathrm{Bi}=2.0$ 은 $23 \rightarrow 40$ 으로 소결온도가 높아짐 에 따라 높아지는데, 특별히 $1,000{ }^{\circ} \mathrm{C}$ 시편은 상대밀도 가 $87 \%$ 임에도 불구하고 높은 비선형성 $(a=23)$ 을 나타 내는 것은 미세구조적으로 살펴본 것과 같이 소결 단 계에서 $\mathrm{Py}$ 의 분해에 의한 $\mathrm{Bi}$-rich상의 생성으로 치밀 화가 진행된 후 냉각 시 $\mathrm{Bi}-$ rich 액상이 $\mathrm{Py}$ 의 재합성 에 소비되는 중에 $\mathrm{ZnO}$ 입계에는 이중 Schottky 장벽 의 형성을 유도하기 때문으로 사료된다 [1]. $\mathrm{Sb} / \mathrm{Bi} \leq$ 1.0 의 경우, 소결온도가 높아짐에 따라 각각 $47 \rightarrow 26$, $50 \rightarrow 36$ 으로 감소하는데 이는 $\mathrm{Bi}$-rich상의 고온 휘발 로 입계에서의 역할이 축소되었기 때문으로 판단된다 [1,21].

따라서 $\mathrm{ZBS}$ 계에 $\mathrm{Co}$ 의 첨가는 $1,000^{\circ} \mathrm{C}$ 의 $\mathrm{Sb} / \mathrm{Bi}=2.0$ 인 조성을 제외하면 전체적으로 바리스터 특성을 크 게 개선시키는 효과를 나타내었다.

\subsection{IS \& MS 분석}

그림 5 는 $\mathrm{ZBSCo}(\mathrm{Sb} / \mathrm{Bi}=0.5)$ 시편을 $1,300{ }^{\circ} \mathrm{C}$ 에서 소 결한 후 주파수와 온도에 대해 IS \& MS 측정결과를 나타낸 것으로 (a) $-53 \sim 27^{\circ} \mathrm{C}$ 영역에서의 $\mathrm{M}^{\prime \prime}-\operatorname{logf}$ 를, (b) $Z^{\prime \prime}-\operatorname{logf}\left(207^{\circ} \mathrm{C}\right)$ 와 $\mathrm{M}^{\prime \prime}-\operatorname{logf}\left(207 \sim 487^{\circ} \mathrm{C}\right)$ 를 나타내 었으며, (c)는 $\ln \rho, \ln \tau$ vs. 1,000/T plot을, (d)는 입계 저항 $\left(\mathrm{R}_{1,2}\right)$ 과 입계 정전용량 $\left(\mathrm{C}_{1,2}\right)$ 을 계산하여 나타낸 것이다.

그림 5(a)와 같이 상온 이하의 온도에서 측정한 $\mathrm{M}^{\prime \prime}-\operatorname{logf}$ 그래프는 특정 결함에 해당하는 $\mathrm{P} 1$ 이 확인 되었고, 각 피크에 대하여 아레니우스 플롯하여 그 활성화 에너지를 계산한 결과 $\mathrm{E}_{\mathrm{bt}}=0.33 \mathrm{eV}$ (그림 5 (c) 참고)로 나타났는데, 이는 본 계의 주 결함이 $V_{o}^{*}$ 임을 알 수 있다 [1,14,15,21-23]. 또한 주된 결함으로 확인 된 $V_{o}^{*}$ 의 저항과 정전용량은 각각 $\mathrm{R} 1, \mathrm{C} 1$ 으로 그림 $5(\mathrm{~d})$ 와 같이 계산되었다. 결함 $\left(V_{o}^{*}\right)$ 으로 인해 발현하 는 저항(R1)은 온도에 따라 지수적으로 감소하지만 정전용량 $\mathrm{C} 1(4.9 \rightarrow 4.0 \mathrm{nF})$ 은 온도가 높아짐에 따라 감소하였다. 이와 같이 결함의 온도에 대한 저항과 정전용량의 변화는 고유한 물성으로 판단되지만 보다 정확한 해석을 위해서는 추가적인 연구가 필요할 것 으로 사료된다.

그림 5(b)에는 상온 이상의 온도에서 측정한 $Z^{\prime \prime}-\operatorname{logf}\left(207^{\circ} \mathrm{C}\right)$ 와 $\mathrm{M}^{\prime \prime}-\operatorname{logf}\left(207 \sim 487^{\circ} \mathrm{C}\right)$ 로 표현되는 입 계 특성을 나타내고 있다. 여기서 $\mathrm{P} 2 \mathrm{Z}$ 와 $\mathrm{P} 4_{\mathrm{M}}$ 의 피크 로 볼 때 입계는 전기적으로 단일 입계를 형성하고 있음을 알 수 있다. 이는 $\mathrm{RC}$ (병렬)가 1 개로 구성된 

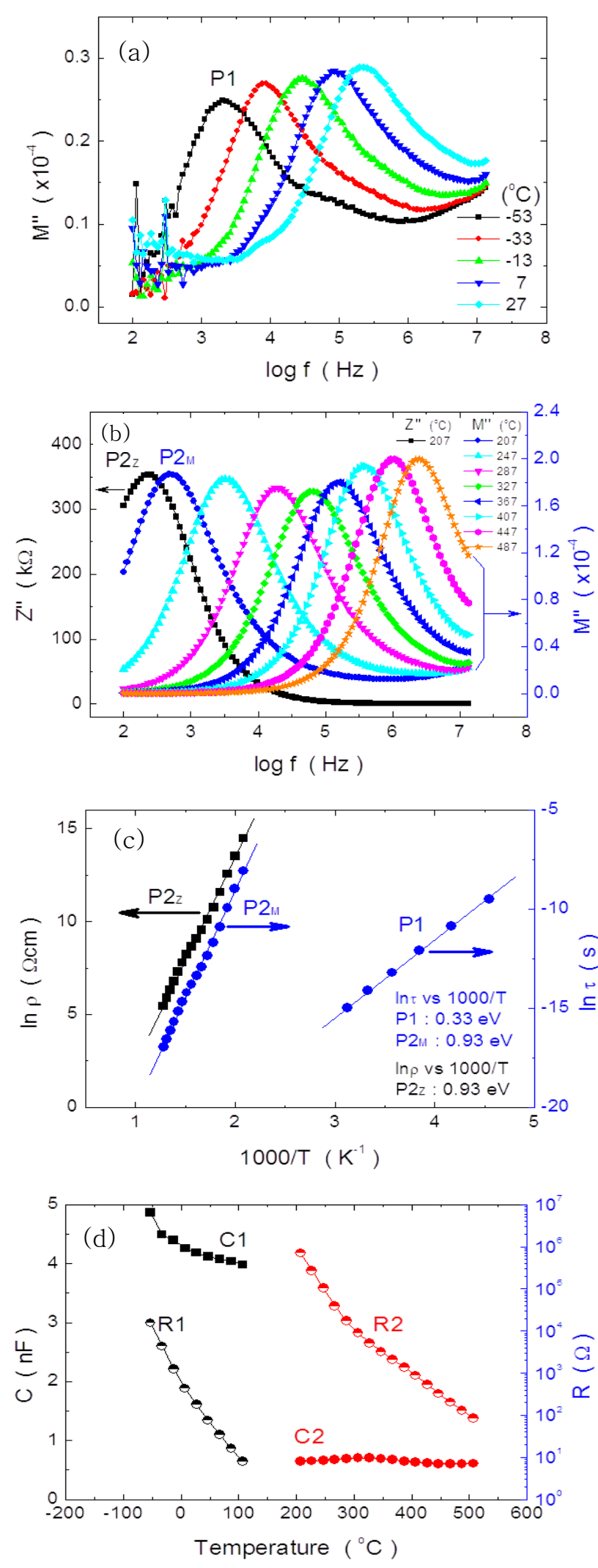

Fig. 5. Impedance and modulus spectroscopy of ZBSCo $(\mathrm{Sb} / \mathrm{Bi}=0.5)$ sintered at $1,300^{\circ} \mathrm{C}$. (a) $\mathrm{M}^{\prime \prime}-\log f\left(-113 \sim-67^{\circ} \mathrm{C}\right)$, (b) $Z^{\prime \prime}-, \mathrm{M}^{\prime \prime}-\operatorname{logf}\left(207 \sim 307^{\circ} \mathrm{C}\right.$ ), (c) $\ln \rho$ and $\ln \tau$ vs. $1,000 / \mathrm{T}$ plot, (d) resistance $\left(\mathrm{R}_{1,2}\right)$ and capacitance $\left(\mathrm{C}_{1,2}\right)$ with temperature.

입계로 볼 수 있다. 각 피크에 대한 저항과 시정수에 대하여 아레니우스 플롯을 통하여 각 입계의 활성화 에너지를 계산한 결과, $\mathrm{P} 2 \mathrm{Z}_{\mathrm{Z}}$ 아 $\mathrm{P} 4_{\mathrm{M}}$ 모두 $\mathrm{E}_{\mathrm{a}}=0.93 \mathrm{eV}$ 로 계산되었다 (그림 5(c) 참고). 그리고 $207^{\circ} \mathrm{C}$ 에서 입계 저항과 정전용량은 각각 $0.7 \mathrm{M} \Omega$ 과 $0.65 \mathrm{nF}$ 으로 계산 되었으며, 저항은 온도에 대해 지수적으로 감소하고 정전용량은 거의 일정 $(0.6 \sim 0.7 \mathrm{nF})$ 하게 유지하였다.

따라서 $\mathrm{ZBS}(\mathrm{Sb} / \mathrm{Bi}=0.5)$ 계에 $\mathrm{Co}$ 를 첨가할 경우, 입 계는 $\mathrm{RC}$ 가 1 개로 구성된다고 할 수 있는데, 이는 등 가회로적으로 $\mathrm{RC} 1$ 개로 구성된 $\mathrm{ZBS}(\mathrm{Sb} / \mathrm{Bi} \geq 1.0)$ 계와 동일한 입계 구조이지만, $\mathrm{RC}-\mathrm{RC}$ 인 2 중 입계를 보이는 $\mathrm{ZBS}(\mathrm{Sb} / \mathrm{Bi}=0.5)$ 계와 여기에 $\mathrm{Mn}$ 이나 $\mathrm{Ni}$ 혹은 $\mathrm{Cr}$ 을 첨 가한 조성계와는 차이가 나는 것이다 [4,12,15,21-23].

그러므로 $\mathrm{Co}$ 첨가제는 일반적으로 $\mathrm{Sb} / \mathrm{Bi}=0.5$ 인 $\mathrm{Bi}-$ rich 액상량이 상대적으로 많은 $\mathrm{ZnO}$ 바리스터에서 보이는 등가 회로적으로 누설전류에 영향을 주는 $\mathrm{ZnO}-\mathrm{Bi}_{2} \mathrm{O}_{3}(\mathrm{Co})-\mathrm{ZnO}$ 입계와 바리스터 거동을 나타내는 $\mathrm{ZnO}-\mathrm{ZnO}$ 입계로 구분 해서 보는 이런 구분을 없앨 수 있는 첨가제라는 것을 알 수 있다 $[4,12,15,21-23]$.

즉, $\mathrm{ZBS}(\mathrm{Sb} / \mathrm{Bi}=0.5)$ 계에 $\mathrm{Co}$ 를 첨가하면 입계를 구 성하는 이러한 두 가지 입계를 거의 동일한 전기적 물성을 갖도록 만드는 역할을 한다고 볼 수 있겠다. 한편으로 $327^{\circ} \mathrm{C}$ 전후로 입계 저항 $(\mathrm{R} 2)$ 과 정전용량 (C2)의 변화 양상 (그림 $5(\mathrm{~b}, \mathrm{c}, \mathrm{d})$ 참고)을 고려할 때 $\mathrm{Co}$ 를 첨가한 입계도 어느 정도 주위 산소의 흡탈착과 관련된 영향을 포함하는 것을 알 수 있다 [12,21-23].

요약하면, $\mathrm{ZBS}$ 계에 $\mathrm{Co}$ 를 첨가할 경우, $V_{o}^{*}(0.33$ $\mathrm{eV})$ 를 주 결함으로 생성하여 바리스터 열화에 큰 영 향을 주는 $Z n_{i}^{*}$ 의 생성을 억제시키고 [1,14-18], 입계 는 전기적으로 단일 입계 $(0.93 \mathrm{eV})$ 를 형성하며, 입계 의 정전용량은 $0.60 \sim 0.70 \mathrm{nF}$ 범위의 값을, 입계 저항 은 온도에 따라 지수적으로 감소하는 경향을 나타내 었다. 


\section{4. 결 론}

$\mathrm{ZBS}$ 계에 $\mathrm{Co}_{3} \mathrm{O}_{4}$ 를 $1 / 3 \mathrm{~mol} \%$ 첨가한 $\mathrm{ZBSCO}$ 계에서 나타나는 소결 및 전기적 특성에 대하여 분석한 결과 다음과 같은 결론을 얻었다.

$\mathrm{ZBSCo}$ 계의 소결과 전기적 특성은 $\mathrm{Sb} / \mathrm{Bi}$ 비에 의 해 제어되었다. 파이로클로어는 $\mathrm{Sb} / \mathrm{Bi}$ 비와 관계없이 전체 계에서 생성되었으며, $\mathrm{Sb} / \mathrm{Bi} \geq 1.0$ 일 때 $\beta$-스피 넬이, $\mathrm{Sb} / \mathrm{Bi}=0.5$ 일 때 $\beta$-스피넬은 사라지고 $\beta-\mathrm{Bi}_{2} \mathrm{O}_{3}$ 를 우선적으로 생성하였다. $\mathrm{Sb} / \mathrm{Bi} \geq 1.0$ 인 계는 파이로 클로어와 스피넬의 생성으로 $900^{\circ} \mathrm{C}$ 까지 치밀화가 억 제되었으며, $\mathrm{Sb} / \mathrm{Bi}=0.5$ 인 계는 공정액상의 생성으로 $800{ }^{\circ} \mathrm{C}$ 부터 치밀화가 촉진되었다. $\mathrm{Co}$ 의 첨가에 따라 $\mathrm{Sb} / \mathrm{Bi}=1.0$ 조성에서 가장 균일한 미세구조를 형성하 였으며, 전체 계에서 높은 비선형 특성(비선형 계수, $\mathrm{a}=23 \sim 50)$ 을 나타내었다. $\mathrm{Co}$ 의 첨가에 의해 계는 $V_{o}^{*}$ $(0.33 \mathrm{eV})$ 를 주 결함으로 생성하여 바리스터 열화에 큰 영향을 주는 $Z n_{i}$ 의 생성을 억제시키는 역할을 하 였다. 입계는 전기적으로 단일 입계 $(0.93 \mathrm{eV})$ 를 형성 하였으며 주위 산소에 의해 다소 영향을 받았다. 따 라서 $\mathrm{ZnO}$ 바리스터에서 $\mathrm{Co}_{3} \mathrm{O}_{4}$ 를 첨가제로 사용할 경 우, 바리스터 특성을 크게 개선시킬 수 있으므로 $\mathrm{Sb} / \mathrm{Bi}$ 비를 잘 고려해서 상발달과 치밀화 및 미세구 조의 균일화를 유도하여 신뢰성을 확보하는 것이 중 요할 것으로 판단된다.

\section{REFERENCES}

[1] D. R. Clarke, J. Am. Ceram. Soc., 82, 485 (1999).

[2] T. K. Gupta, J. Am. Ceram. Soc., 73, 1817 (1990).

[3] K. Eda, IEEE Elec. Insulation. Mag., 5, 28 (1989).

[4] R. Einzinger, Ann. Rev. Mater. Sci., 17, 299 (1987).

[5] L. M. Levinson and H. R. Philipp, Am. Ceram. Soc. Bull., 65, 639 (1986).

[6] Y. W. Hong, Bull. KIEEME, 24, 3 (2011).
[7] M. Inada,, Jpn. J. Appl. Phys., 18, 1439 (1979).

[8] M. Inada and M. Matsuoka, Advances in Ceramics (American Ceramic Society, Columbus, 1983) p. 91.

[9] J. Kim, T. K. Kimura, and T. Yamaguchi, J. Am. Ceram. Soc., 72, 1390 (1989).

[10] A. Mergen and W. E. Lee, J. Eur. Ceram. Soc., 17, 1049 (1997).

[11] Y. W. Hong and J. H. Kim, J. Kor. Ceram. Soc., 37, 651 (2000).

[12] Y. W. Hong, H. S. Shin, D. H. Yeo, J. H. Kim, and J. H. Kim, J. KIEEME, 21, 738 (2008).

[13] L. Karanović, D. Poleti, and D. Vasović, Mater. Lett., 18, 191 (1994).

[14] F. Greuter and G. Blatter, Semicond. Sci. Technol., 5, 111 (1990).

[15] Y. W. Hong and J. H. Kim, Ceram. Int., 30, 1307 (2004).

[16] J. Han, P. Q. Mantas, and A. M. R. Senos, J. Euro. Ceram. Soc., 22, 49 (2002).

[17] M. H. Sukker and H. L. Tuller, Advances in Ceramics (American Ceramic Society, Columbus, 1983) p. 71.

[18] G. D. Mahan, J. Appl. Phys., 54, 3825 (1983).

[19] K. A. Abdullah, A. Bui, and A. Loubiere, J. Appl. Phys., 69, 4046 (1991).

[20] M. Andres-Verges and A. R. West, J. Electroceram., 1, 125 (1997).

[21] Y. W Hong, H. S. Shin, D. H. Yeo, J. H. Kim, and J. H. Kim, J. KIEEME, 22, 941 (2009).

[22] Y. W. Hong, H. S. Shin, D. H. Yeo, and J. H. Kim, J. KIEEME, 23, 368 (2010).

[23] Y. W. Hong, H. S. Shin, D. H. Yeo, and J. H. Kim, J. KIEEME, 23, 942 (2010).

[24] H. R. Philipp, Materials Science Research, Tailoring Multiphase and Composite Ceramics (eds. R. E. Tressler, G. L. Messing, C. G. Pantano, and R. E. Newnham) (Prenum Press, New York/London, 1987) p. 481. 